Portland State University

PDXScholar

1974

\title{
An Investigation of the Influence of Dialectal Interferences on the NSST Scores Obtained by Portland Black Children
}

Margaret J. Callahan

Portland State University

Follow this and additional works at: https://pdxscholar.library.pdx.edu/open_access_etds

Part of the Speech and Hearing Science Commons, and the Speech Pathology and Audiology Commons

Let us know how access to this document benefits you.

\section{Recommended Citation}

Callahan, Margaret J., "An Investigation of the Influence of Dialectal Interferences on the NSST Scores Obtained by Portland Black Children" (1974). Dissertations and Theses. Paper 2051.

https://doi.org/10.15760/etd.2050

This Thesis is brought to you for free and open access. It has been accepted for inclusion in Dissertations and Theses by an authorized administrator of PDXScholar. Please contact us if we can make this document more accessible: pdxscholar@pdx.edu. 
AN ABSTRACT OF THE THESIS OF Margaret J. Callahan for the Master of Science in Speech: Emphasis in Speech Pathology/ Audiology presented May 9, 1974.

Title: An Investigation of the Influence of Dialectal Interferences on the NSST Scores Obtained by Portland Black Children.

APPROVED BY MEMBERS OF THE THESIS COMMITTEE:

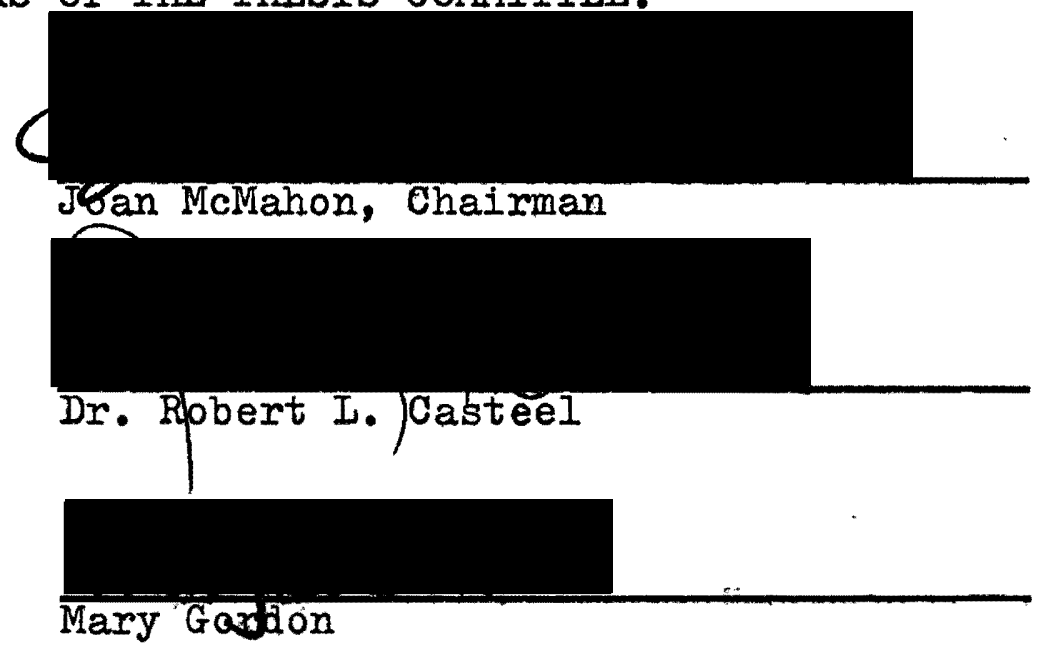

The primary purpose of this study was to determine if dialectal interference as described by Walter Wolfram (Appendix B) was exhibited by black children in Portland, Oregon when given the NSST by Laura Lee. This author was concerned with syntactical interferences on the expressive portion of this test.

A secondary purpose of this investigation was to provide suggested norms for differentiating children with 
language deficits from children with language differences. Seventy black children with normal speech and language were selected from two public schools, a Head start Center and a day care center. These children were between the ages of 3-0 to 7-11 and had been screened to determine their race, age, socioeconomic status, and emotional stability. Screening for intelligence was performed at the beginning of the testing situation, before the expressive portion of the NSST was administered. The NSST consists of sentence repetition in response to pictures. The sentences involve grammatical contrasts of increasing difficulty, and can be administered in five to ten minutes. The results of this study did not support the prediction made by this researcher. 
AN INVESTIGATION OF THE INFLUENCE OF DIALECTAI INTERFERENCES ON THE NSST SCORES OBTAINED BY PORTIAND BIACK CHILDREN

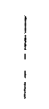 \\ by \\ MARGARET JEANNE CALIAHAN
}

A thesis submitted in partial fulfillment of the requirements for the degree of

\title{
MASTER OF SCIENCE
}

SPEECH: EMPHASIS IN SPEECH PATHOLOGY/AUDIOLOGY

Portland State University

1974 
TO THE OFFICE OF GRADUATE STUDIES AND RESEARCH:

The members of the Committee approve the thesis of Margaret J. Callahan presented May 9, 1974.

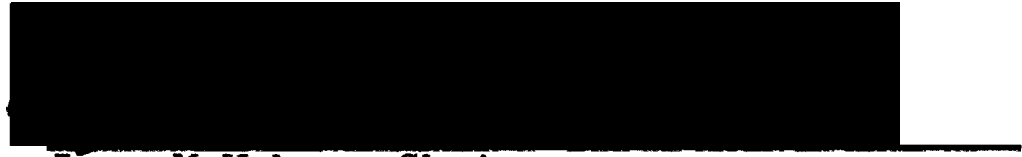

Joan Meliahon, Chairman

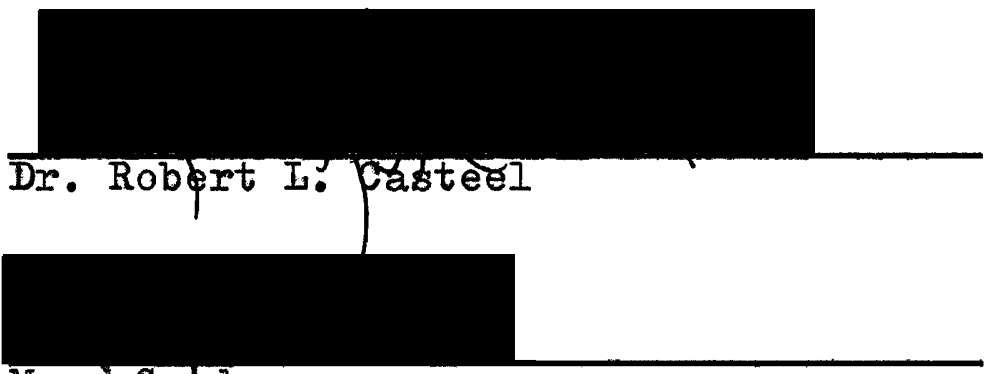

Mary Getaon

\section{APPROVED:}

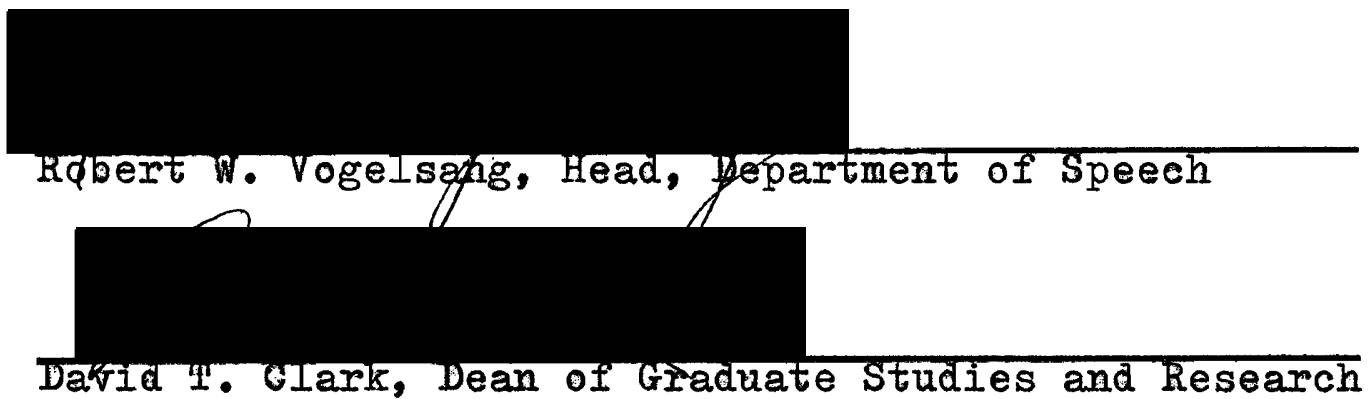

May 17, 1974 


\section{ACKNOWLEDGMENTS}

It is a pleasure to express gratitude and appreciation to my chairman and my friend, Joan MoMahon for her time and effort spent with me in the planning and completion of this study. Acknowledgment to the members of my committee, Dr. Robert Casteel, Dr. Joe Pierce, and Mary Gordon. Fervent thanks are also extended to Dr. Jack Hegrenes for his help and patience in the analysis of the data collected.

Finally, I would like to express my deep appreciation to my parents for their total support and understanding throughout this period of graduate study. 
TABIE OF CONTENTS

PAGE

ACKNOWLEDGMENTS . . . . . . . . . . . .

IIST OF TABIES. . . . . . . . . . . . . . vi

IIST OF FIGURES . . . . . . . . . . . . . vii

CHAPTER

I INTRODUCTION. •. . . . . . . . . 1

II REVIEW OF THE IITERATURE. . . . . . . 5

What Are the Rules Which Govern Black English?. . . . . . . . 7

Should Black Children Learn Standard.

English?........... 8

Should Black English Be Used in the Schools?.............. 10

Do Negative Teacher Attitudes Toward Nonstandard Dialects Inhibit the Iearning Situation? ...... 11

What Should Be Done About It? . . . 13

III METHODS AND PROCEDURES. • . . . . . 17

Subjects. . . . . . . . 17

Variables . . . . . . . 18

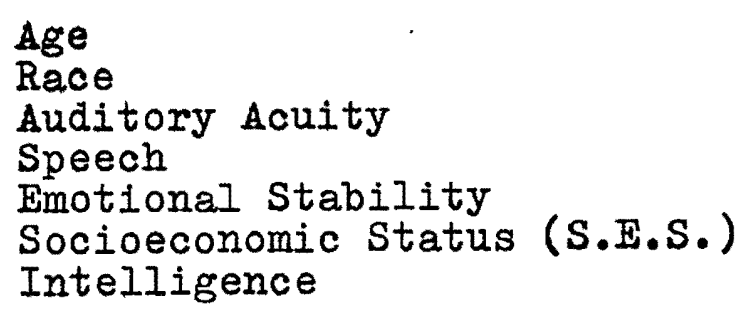


Instrumentation . . . . . . .

Test Administration

Scoring

Reliability

Data Analysis

IV RESUITS AND DISCUSSION. . • • • • •

Results •. •. . . . . . . .

Discussion. . . . . . . . .

$$
\text { SUMT }
$$

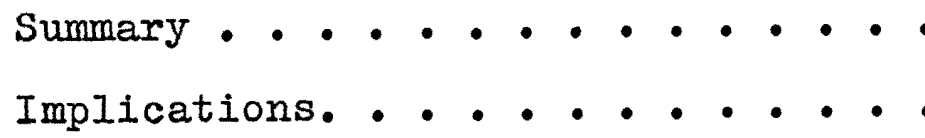

CInic

Research

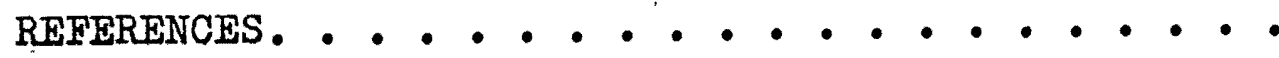

\section{APPENDICES}

A NORTHWESTERN SYNTAX SCREENING TEST RECORD

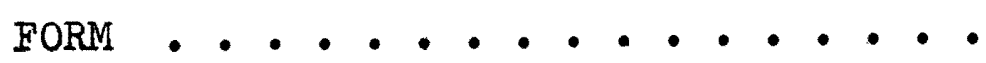

$B$ PREDICTED DIALECT INTERFERENCE AS DES-

CRIBED BY WAITER WOIFRAM ON NSST. • • $\quad 54$

C RUIES FOR SCORING THE NSST, - • - • •

D SAMPIES OF IEE, WOLFRAM, AND IDIOSYN-

CRATIC RESPONSES. . . . . . . . 
IIST OF TABIES

TABIE

PAGE

I Intra and Inter Scorer Reliability of

Scorers . . . . . . . . . . .

II Number of Responses in Each of Five

Categories by Age Groups According

to First Scoring . . . . . . .

II Percentage of Children Who Fell Below

the 10th Percentile Mean I.Q. for

Each Age Group. . . . . . . .

IV Mean Scores and Standard Deviations for

Lee, Wolfram and Idiosyncratic

Responses on First Scoring . . . .

$\checkmark$ Number of Responses in Each of Five

Categories by Age Groups According

to Second Scoring . . . . . . . .

VI Number of Children Who Fell Below the

10th Percentile According to the

Second Scoring. . . . . . . . .

VII Mean Scores Obtained for Iee, Wolfram, and Idiosyncratic Responses on

Second Scoring. . . . . . . . . 


\section{IIST OF FIGURES}

FIGURE

PAGE

1. Mean Scores for the Portland Black Children on First and Second Scorings and for the Population Used by Iee to Establish Norms on the NSST. . . . . . . . .

2. Number of Responses in Each of Five Age Groups According to the First Scoring • 36

3. Number of Responses in Each of Five Age

Groups According to the Second Scoring. - 38 
CHAPTER I

\section{INTRODUCTION}

Do Blacks have a language of their own? According to linguists such as William A. Stewart, J. I. Dillard, William Lobov, Walter Wolfram, and others, Blacks do have their own language. Labels such as black English, black dialect, nonstandard English and "Merican" are all terms used to refer to a unique and cohesive language system with its own pronunciation and grammatical patterns (Dillard, 1972). For the purposes of this study, this language system will be referred to as black English. The advocates of black English state that it is uniform throughout the country and is a social as opposed to a regional dialect. Wolfram in a lecture on black English at the 1972 ASHA convention in San Francisco made the distinction that regional dialect differs from standard English predominantly in the vowels and a social dialect differs from standard English predominantly in the consonants. According to Williams (1972), black English does have some common elements with standard English, northern white nonstandard and southern white nonstandard dialects, but there is evidence of common and frequently occurring linguistic features predominant among Black speakers which establishes that black English.is a 
systematic language in its own right and not just an approximation of standard English.

The proponents of black English as a distinct language feel that it should be recognized, accepted, and used without stigma. If the fact that black English exists is accepted, the issue becomes practical rather than academic and presents special problems to the educator and more specifically to the speech clinician in the public schools. Black children in school probably face many difficulties in academic subjects and in relationships with white teachers and white peers due to the difference between black English and standard English. Iinguists refer to this as dialectal interference when one phonological and grammatical system interferes with the proficient use of another. The speech clinieian is especially concerned with this situation since it is part of his task to make the distinction between language deficits and language differences. In many testing situations a black child expresses himself in terms of the language which permeates his home and environment. In determining if the child has a given concept, the speech clinician must then decide whether to evaluate the black child on the basis of given norms or whether to use his own judgment. For this reason, Wolfram (1972) and others feel that it is imperative to reassess our tools of diagnosis and appraisal; that many of these tools are dialectally biased against black children. This researcher has 
attempted to reassess the Northwestern Syntax Screening Test (NSST) by Laura Lee through administering the NSST to Portland black children to determine if they display dialectal interference in their responses.

The NSST is an instrument which was developed to identify children between the ages of 3 and 8 years who are delayed in syntactic development. Lee (1970) stated:

It makes a comparison between expressive and receptive use of such grammatical features as prepositions, personal pronouns, negatives, plurals, reflexive pronouns, verb tenses, subject-object identification, possessives, wh-questions, yes-no questions, passives, and indirect objects.

This study was concerned only with the expressive portion of the NSST (Appendix A). At the 1972 ASHA convention, Wolfram presented material which predicted the dialectal interferences or black English one would get when giving the NSST to a black child (Appendix B). The predictions were based on Wolfram's experiences with black children and were not the result of a formal study. This researcher felt it would be beneficial to determine if black children in Portland exhibited dialectal interference on the NSST as described by Wolfram. The analysis of the responses given on the expressive portion of this test would aid the speech clinician in Portland to better assess a language difference from a language deficit when dealing with a black child.

\author{
STATEMENT OF THE PROBIEM
}

The primary purpose of this study was to determine if 
dialectal interference as described by Walter Wolfram (1972) is exhibited by black children in Portland, Oregon, when given the expressive portion of the NSST by Iaura Lee. This researcher predicted that Portland black children would exhibit dialectal interference as described by Walter Wolfram (1972).

A secondary purpose of this investigation was to provide suggested norms for differentiating children with language deficits from children with language differences. 
CHAPTER II

REVIEW OF THE IITERATURE

In the past decade there have evolved new and exciting philosophies concerned with language standards and expectancies. The evolution of these philosophies was accelerated by the Civil Rights Movement of the 1950's and 1960's when, in a most dramatic way, minority groups told America they indeed existed and demanded to be recognized. In essence they rejected the "melting pot" theory and indicated they did not intend to conform to the ideals and standards of white middle class America in order to reap the benefits of equal opportunity.

From this came a growing concern and awareness of the inadequate educational conditions of children from low social class. Many programs such as Head Start, Follow Through, and the Berieter and Engelmann Program concerned with language enrichment and intervention for the preschool child were developed and funded from federal, state, or private foundations. Researchers in the areas of education and psychology have identified three low socio-economic groups: culturally deprived; linguistically deprived; and socially disadvantaged (Bernstein, 1970). They generally agreed that the disadvantaged children in these three 
groups were at least one year delayed in their language (Fine, 1972) when being appraised against a white middle class norm. This precluded the possibility of disadvantaged children having a systematic language of their own and assumed they possessed a language system which was an approximation of standard English. Baratz (1970b) referred to this as the deficit model. Iinguists were the first to dispute the educator's and psychologist's view with the contention that the culturally deprived child had a system which was just as functional and logical as that of the white middle class child but which was different in some essential structures. Baratz (1970b) appropriately labelled this the difference model.

According to linguists, language is an arbitrary set of structured vocal symbols (Pierce, 1972). It is basic to linguistic philosophy that all humans develop language, and that language is a well-ordered system with predictable sound patterns, grammatical structure, and vocabulary (Baratz, 1970a). Several assumptions which are basic to the linguistic view of language were stated by Wolfram (1970): First, verbal systems are arbitrary, established only by convention; second, all languages or dialects are adequate as communicative systems; and third, one must observe that language is learned in the context of the community. Having accepted these premises the linguist views languages as different rather than qualifying one as better 
or more correct than another. In viewing black language, Baratz (1970b) stated there are two basic models: the deficit model; and the difference model. These models may seem overly simplistic, yet Wolfram (1970) feels they are a helpful framework for theoretical approaches to nonstandard dialects. He also considers them of practical value in that if nonstandard dialect is considered to be a crude approximation of standard English, important syntactical facts about the nature of these dialects will be missed.

Accepting the premise that the language of the disadvantaged black child is a systematic dialect, several questions are presented: What are the rules which govern black English? Should black children learn standard English? Should black English be acknowledged in the schools via reading materials in black dialect? Do negative attitudes toward nonstandard dialects by teachers inhibit the learning situation? What should be done about it?

What Are the Rules Which Govern Black English?

Since this study was concerned with the syntax of black English the following rules pertain only to syntax and do not include phonological or sematic rules. According to Williams (1972) these syntactic structures are highly characteristic of black English. 
Structure

1. Third person singular

2. Possessive /-s/

3. Copula Absence

4. Invariant "Be"

5. Verb Agreement

6. Negation

7. Multiple Neg.

8. Plurals

9. Past Forms

10. Future
Black English

he care

the girl book

he a barber

he be gone

they was there

he dit'n run

nobody don't know

he took five book he took five books

he crack the whip he cracked the whip

he gonna sing
Standard English

he cares

the girl's book

he's a barber

he is repeatedly gone

they were there

he did not run

he will sing

Other similar lists of black English syntactical structures have been formulated by Povich and Baratz (1967), Baratz (1968) and Fasold and Wolfram (1970).

Should Black Children Learn Standard English?

Wolfram (1970) feels that the black child should learn standard English. He contends that a usable knowledge of standard English is necessary because, in the rigid structure of society black English is not acceptable to many people. Baratz (1969a) feels that it is necessary for the black child to learn standard English in order to function in the mainstream of society. A study by Baratz (1969c) found that black children were not generally bidialectal, that there was evidence of interference from 
their dialect when the children attempted to speak standard English. She concluded that language assessment must involve measures of the black child's knowledge of black English as well as his knowledge of standard English. Baratz (1969f) states:

If the criterion for language development is the use of a well-ordered systematic code, then the continued use of measures of language development that have standard English as the criterion of a developed form will only continue to produce the results that the Negro lower-class child is delayed in language development because he has not acquired the rules that the middle-class child has been able to acquire, that is, his language is underveloped.

She contends that the black child should be introduced to standard English early for, by giving him a workable knowledge of standard English, he is then in a position to choose whether or not to use it. Seymour (1971) agrees with this position and feels that by not giving a child a chance to be bi-dialectal he is being restricted severely because our education system at this stage is not geared polyculturally and school tests especially are geared to the white middle class chlld. Blank (1970) contends that language has emerged as the common denominator of the learning deficit and has led many educators to believe that language is at the core of difficulty for the disadvantaged child. She states the need for a program geared toward development of standard English since it is an integral tool in the school situation. In addition, Baratz (1969b) and Burks and Polly (1969) contend that it is necessary for 
black children to learn standard English.

Should Black English Be Used in the Schools?

To many it is essential to have school texts written in black English. For example, Shuy (1971) states that teaching materials which have the grammatical features found in the dialect of the child should be used. Seymour (1971) points out some experiments where materials were written in black syntax have aided the reading ability of black children. The need for acknowledgment of black English in the schools through reading materials as well as verbally is recognized also by Bromwich (1968), Baratz (1969c), and Ericksen (1969). They feel that this is essential to communication in the classroom. Kenneth Johnson (1971) also feels black children should be permitted to use their black dialect in the school setting and they should be taught to read in their dialect. In order to accomplish this, a teacher must be familiar with the structure of black dialect in order to use it as a tool for academic studies as well as for gaining a basic understanding of the dialect itself. Blank (1970) contends the knowledge of the structure of a nonstandard language is an invaluable tool in determining whether or not a child's language is typical and consistent with his community. In regard to the demanded use of standard English by black children in the schools, Menyuk (1971) feels that because of this demand many problems are 
encountered in the education of the disadvantaged child from a low income family. She states that this is reason enough for a reevaluation of the tasks that these children are given to do and the way in which they are taught to accomplish these tasks. Menyak (1970) states it is necessary to understand which rules the child must acquire, which he must modify, which will cause conflict and difficulty, and which may be easily acquired. She states further that familiarity with both the structural and psycholinguistic descriptions can be very helpful in planning curriculum.

The educator can evaluate the effectiveness of this program by measuring the changes in the degree of deviancy in terms of the structural descriptions at the phonological, morphological and syntactic levels of grammar that a child is using after a period of time (Menyuk, 1970).

Severson and Kristin (1970) point out that in evaluations using standardized language tests only one type of response is correct. The tester is then faced with the choice between normative language usage in the community of the child being tested or some set of standards judged as the desired language capabilities for the child. In order to make this choice it is necessary to be familiar with the dialect of the community.

Do Negative Teacher Attitudes Toward Nonstandard Dialects Inhibit the Learning Situation?

H. Johnson (1971) feels speech deviations or dialects inhibit both the teacher and students and prevents them 
from embarking upon meaningful language activities. He states this is probably due to the teacher's resistance to the dialect and her resolution to perpetuate correct grammar. It is suggested the language used by the child should be encouraged and this would enable him to increase his language ability. Kenneth Johnson (1971) feels that negative attitudes of teachers result from their lack of understanding of the phenomenon that linguists label interference. He defines interference to be those features of black English which differ from standard English and these phonological and grammatical systems get in the way of attempts to speak standard English. Johnson feels that black children only partially learn standard English because they mix features of their dialeet and standard English much like a foreign speaking person tends to do: Baratz (1972) defines linguistic interference as the knowledge of one linguistic system interfering with the performance in another. Kochman (1972) states that interference refers to those deviations or distortions which are made by the speaker as a result of conflicting norms. In regard to black English Kochman feels that some teachers define their role as the socializing agent of the dominant culture and feel it their duty to mold the child into an acceptable form for society. This type of teacher applies standard language rules to every child and these rules are more often based on myth than on historical processes and 
development. He states that the inevitable clash between these static rules and the dynamic flow inherent in actual language use brought about the necessity for a descriptive approach to language rather than a prescriptive approach. He defines the prescriptive approach as one in which rules determine usage and the descriptive approach as one in which the usage determines the rules.

What Should Be Done About It?

According to Bernstein (1970) it is an accepted educational principle that educators should work with what the child has to offer. Yoder (1970) feels that the educator's basic goal is one of parallel development along the lines of an aditional linguistic system. He feels the most important thing one should know concerning dialects is the contrasts between a target language or dialect and the child's existing language or dialect and states:

- . this calls for knowledge and information about the existing dialect being used by a child and the understanding that dialects by their very genesis may have evolved to accomplish different communitive tasks and thus are to be preserved.

Wolfram (1970) agrees with this view and states:

An understanding of systematic differences between nonstandard dialects and standard English must serve as a basis for the most effective teaching of standard English.

Williams (1970) contends the culturally disadvantaged child experiences normal language development and schools should be able to build upon what the child already knows. 0ther- 
wise he feels that the schools promote cultural depreciation and eventual self-depreciation of the child. In addition to this, when a child is not allowed to speak in the dialeet which is normal to him, his communicative abilities are severely stifled. Williams feels the first step toward resolving this is to make the schools poly-culturally oriented. In order to do this it is necessary for educators to know what constitutes the structure, vocabulary, and phonology of a dialect. Baratz (1970) contends one must recognize that the nonstandard speaking child has a language which is well ordered but different in many respeots from standard English and this concept is crucial to understanding how to educate the black child. Wolfram (1971) and Alder (1971) feel that appraising descriptive facts and providing detailed mapping of dialects and behaviors of the children with whom one is dealing are necessary and essential jobs upon which intervention programs can be based. Alder (1973) points out that the schools traditionally have tried and failed to eliminate what is thought of as uneducated speech. He suggests, as dialectal patterns can be beneficial to their users, they will not be given up easily and rather than changing these dialectal patterns it is a responsibility of the teacher to learn and use them. To do this, Shuy (1970) states that the sociolinguist begins answering questions about black dialect by describing the dialect in question with all the rigor available to them. They then 
compare the results with the description of any other language or dialect most likely the target dialect for formal education. Lobov (1970) forcefully condemns the deficit position held by some in the area of education and contends that language must be looked at descriptively. In order to accomplish this, preconceived notions and the assumption that black English is an approximation of standard English must be eliminated. He states that the black child's environment is verbally rich and logical, and one must understand nonstandard English to see this. H. Johnson (1971) and Shuy (1971) agree that it is essential for the classroom teacher to have an understanding of the dialects of the ohildren they encounter, and to accomplish this the teacher must be familiar with the descriptive and analytical aspects of the dialect.

Intervention programs geared strictly for preschool children of culturally different backgrounds are advocated by Brassiel (1962), Caldwell (1964), Bereiter and Engelmann (1966), Brittain (1966), Cazden (1966), and Classen (1969). These programs are aimed primarily at language enrichment and other academic abilities a child needs to have in order to function in the classroom.

When the information collected on black English is examined, one can see that it is a consistent and systematic language. Since researchers, educationalists, sociologists, and psychologists are recognizing this, the problems faced 
are many, and steps need to be taken to solve these problems. This writer felt there was a need in the Portland area to describe the syntax used in the black community and to make use of this information in dealing with speech and language pathologies.

According to Lee (1970) the assessment of syntactic development in children has been the subjective judgment of a clinician based largely upon informal conversation with the child who is being evaluated. Thus the clinician in this type of setting must judge without reference to specific linguistic tasks, developmental scales, or norms. There have been several tests developed which are designed to evaluate various aspects of grammatical skill, among these are Berko's (1958) method for investigating morphological development, the Michigan Picture Language Inventory by Learea (1958), the Imitation, Comprehension, Production Test (ICP) by Fraser, Brown and Bellugi (1963), Carrow's (1968) investigation of auditory comprehension of language structure, the Grammatic Closure Subtest of the Illinois Test of Psycholinguistic Abilities by Kirk, MeCarthy and Kirk (1968), Menyuk's sentence repetition task (1969), and the NSST (Iee, 1970) which was used in this study. 
CHAPTER III

METHODS AND PROCEDURES

\section{SUBJECTS}

Seventy black children with normal speech and language were selected from the Portland Metropolitan Steering Committee-Child Development Division (CDD), the St. Vincent DePaul Day Care Center (SVDP) and the Portland Public Schools (PPS). All henceforth are referred to as schools. All the black children within these schools who were between the ages of 3-0 and 7-11 were screened to determine their race, age, auditory acuity, speech ability, emotional stability, and socioeconomic status (S.E.S.). Screening for intelligence was performed at the beginning of the testing situation. After the inftial screening was complete, all of the potential subjects were then assigned a number and using a random sampling procedure ten children and three alternates were selected for each of the age levels to be tested. Alternate subjects were used if the original child failed the Peabody Picture Vocabulary Test (PPVT), or was Judged not testable. Alternates were also used if the child originally selected was unavailable on the day of testing at the particular school. The screening and random sampling procedures were conducted three times; once at each of the 
schools previously mentioned. At the first school where the children were tested there were 55 potential subjects, at the second school there were 22 and from the third school there were 40 .

\section{VARIABIES}

Variables which were controlled for in this study are race, age, auditory acuity, speech ability, emotional stability, socioeconomic status, and intelligence. Sex was not a variable dealt with for two reasons: Iee (1964) states that out of 131 females and 111 males used to establish tentative norms for the NSST there was no consistent difference found between the boys and the girls; also it was recognized from the beginning of this study that the sample of children available would probably be limited and to include this variable would reduce the number of children in each group.

Age

The ages of the children tested were from 3-0 to 7-11, which corresponds with the age range lee used in her research to gather tentative norms on the NSST. After the children in each school were located and screened the children were grouped according to age in seven groups of ten children each: 


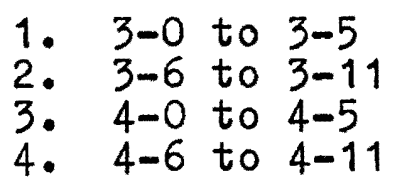

5. 5-0 to 5-11

6. 6-0 to $6-11$

7. 7-0 to $7-11$

The age of each child was determined by subtracting his birthdate from the date he was to be tested. After this subtraction, if the number of days was 15 or over then an additional month was given to the child's age.

\section{$\underline{\text { Race }}$}

All children tested were black. In talking to administrators of the Portland Public Schools it was found that the criterion for determining the race of black children was if a child had two black parents or one black parent and the other a different race the child was considered black. The same criteria was used for this study.

\section{Auditory Acuity}

Normal hearing was determined by consulting the school records, classroom teacher, speech clinician, and school nurse or any combination of these when available.

\section{Speech}

It was felt that the child with a speech disorder or who had received previous speech treatment would not be representative of the black children in Portland and was therefore excluded from this study. Speech was screened by consulting with the classroom teacher, school records, and speech clinician when available. At one of the schools a 
speech clinician was not available nor did the records of these children include information of this nature. Thus, in addition to consulting with the teacher this researcher asked each child to repeat sentences and talk about a picture as a measure of screening the children's speech. This procedure took approximately ten minutes with each child. A decision was then made as to the speech ability of each subject. Since this was the first and only school attended by these children it was concluded that they had not received previous speech treatment.

Emotional Stability

Emotional stability was screened through consultation with the classroom teacher, speech clinician and nurse when available: This was a subjective judgment and they were asked to refer children whom they felt would cooperate and who would not feel threatened by the testing situation. If they felt the child would cry, not respond, or otherwise be adversely affected they were asked not to include him in the number of potential subjects.

\section{Socioeconomic Status (S.E.S.)}

The target sample regarding S.E.S. was a group of subjects which would represent black children in Portland from the lower soclal and economic backgrounds. In reviewing the literature it was found that black dialect prevails in this group rather than in the upper and middle S.E.S. 
groups. For this study, limited by time and resources it was desired to determine socioeconomic status by the occupation of the chief income recipient in the child's family. Yet it was possible to do this only at one of the schools mentioned earlier, SVDP. Since CDD is a federally funded day care center in the model cities area with a criteria of $90 \%$ of the children attending must be in a low S.E.S. group, it was assumed that the children tested from the Follow Through Program the child must come from a low S.E.S. background. In the other Portland Public School, information concerning the children's S.E.S. was obtained by the principal.

In determining S.E.S., by using the occupation of the chief recipient in the child's family the procedure was to assign numerical values ranging from 01 to 40 , these scores represent a range of low income occupations. The occupation of the chief income recipient in the child's family was obtained by first consulting the records on each child which listed the father's occupation and/or employer. When just the employer was listed and not the occupation, a staff member who was familiar with the parents and occupations was consulted. In situations where both parents were employed with the occupation listed for both, the father's occupation was arbitrarily selected for analysis.

\section{Intelligence}

The Peabody Picture Vocabulary Test Form A (Dunn, 1965) 
was utilized in the present study as a method of screening intelligence of the subjects. It is realized that this instrument may reveal only one aspect of intelligence, the child's receptive vocabulary. Yet many feel that it is a useful measure to screen overall intelligence in that it correlates highly with the Wechsler Intelligence Scales for Children (WISC). This test was administered as the first item of a two part test battery. Children who achieved scores between 85 and 115 were then included in the study. Those falling below or above these scores were excluded.

\section{INSTRUMENTATION}

Test Administration

To determine whether or not low income black children in Portland exhibit dialectal interference on the NSST the expressive portion of this test was administered. This portion consists of sentence repetition in response to pictures and involve grammatical contrasts of increasing difficulty. The examiner administered this test as well as the PPVT individually to each child. The examiner and child sat at a table on which the pictures were put out in front of the child. The examiner directed the child to look at the pictures and listen while the examiner talked about them and was asked to say exactly what the examiner said. A tape recorder was used to record the child's responses so that the examiner would be able to score the child's responses as accurately 
as possible. The total time spent with each child varied, usually with age, resulting in a longer period of time spent with the younger ones. The amount of time ranged from twenty minutes to a maximum of thirty minutes. Children evaluated in this manner had previously been screened for race, S.E.S., speech, auditory acuity, emotional stability, and age.

\section{Scoring}

The examiner scored the responses once in the actual testing situation and no more than three times from the tape. In scoring the test the instructions indicate a score of 1 is given for each correct response. If both Items in a sentence pair are correct, the score will be 2; if only one is correct 1; if neither is correct, 0 . Correct expressive answers should be verbatim repetitions of the examiner's model yet it is also stated that replies which accomplish the grammatical test item but which alter the sentence insignificantly and preserve grammatical correctness may be scored correct. In scoring the tapes made during the pilot project a need for a more structured analysis of what would be considered a correct response became apparent and more specific rules on scoring were formulated (Appendix C).

\section{Reliability}

To insure that the examiner was a reliable judge of 
children's syntactical ability, relative to this test, a pilot study was conducted. Subjects were ten children from the Helen Gordon Child Development Center. The only goal at this point was to judge this examiner's skill in giving the NSST and in scoring responses. Auditory acuity, I.Q., speech ability, S.E.S., and race were not controlled. There were five males and five females who ranged in age from 4 years 4 months to 6 years 3 months. The children were tested following the testing format previously described for the NSST and a tape recorder was used to record the responses. After this examiner had established the scoring rules the tests were then given a score. A list of the rules plus the tapes were then given to a speech pathologist holding ASHA C.C.C. In Speech Pathology who was familiar with this research profect and the NSST to score the tests. These two scorings were then analyzed and found to correlate highly in that there was no statistical difference between this examiner and the speech pathologist's scores. The tests were scored again two weeks later to determine intratester reliability and there was no statistically significant difference between either tester's first and second scorings.

\section{Data Analysis}

The data was analyzed in terms of percentages, means and standard deviations. In order to determine the correlation between the children's intelligence quotient and their 
test scores the Spearman's Correlation Test was used.

Item analysis was accomplished by categorizing the responses as follows: No response; Reversal; Lee responses; Wolfram responses; and Idiosyncratic responses. These categories were further defined as:

1. A No response was when the child did not repeat the sentence the examiner had previously said.

2. A Reversal was a grammatically correct response to the incorrect picture.

3. A Lee response was either an echoic, verbatim response or one which followed the guidelines for insignificant alterations as described in Rules for Scoring (Appen$\operatorname{dix}()$ ).

4. A Wolfram response was one which was listed on his handout (Appendix B).

5. An Idiosyncratic response was any response which did not fall into a Lee, Wolfram, No response, or Reversal category.

In Appendix $D$ a sample test illustrates the three predominant types of responses given: (a) Iee; (b) Wolfram; and (c) Idiosyncratic.

To determine if the first set of rules used for scoring had significantly affected the results of this study, the NSST tests were re-scored a second time following a less strict criteria. 
CHAPTER IV

\section{RESULTS AND DISCUSSION}

Results

The results of the pilot study indicated that this examiner (Clinician A) and the speech pathologist holding ASHA C.C.C. in Speech Pathology (Clinician B) correlated very highly in the scoring of responses on the NSST for this project (Table I). Intra Co-Efficient Reliability was 0.8559 for Clinician $A$ and was 0.9624 for Clinician $B$. The Inter Co-Efficient Reliability between Clinician A and Clinician B was 0.9698 and this researcher's ability to score the NSST accurately was deemed adequate.

\section{TABIE I}

INTRA AND INTER SCORER RELIABIIITY OF SCORERS

Comparison

Co-Efficient Reliability

$\begin{array}{ll}\text { Clinician A-A } & 0.8559 \\ \text { Clinician B-B } & 0.9624 \\ \text { Clinician A-B } & 0.9698\end{array}$

When categorizing the 400 possible responses of each 
age group into Lee, Wolfram, Idiosyncratic, No response and Reversals, certain differences are noted (Table II). The responses ranged from 43 Lee, 78 Wolfram, 274 Idiosyncratic, 3 No response, and 2 Reversals for the youngest group tested to 232 Iee, 41 Wolfram, 105 Idiosyncratic, 0 No response, and 22 Reversals for the oldest group tested.

TABLE II

NUMBER OF RESPONSES IN EACH OF FIVE

CATEGORIES BY AGE GROUPS

ACCORDING TO FIRST

SCORING

\begin{tabular}{lrrrrrr}
\hline \multicolumn{1}{c}{ Age } & Lee & Wolfram & Idio. & N.R. & R. \\
\hline 3.0 to 3.5 & 43 & 78 & 274 & 3 & 2 \\
3.6 to 3.11 & 72 & 56 & 265 & 1 & 6 \\
4.0 to 4.5 & 120 & 70 & 206 & 0 & 4 \\
4.6 to 4.11 & 130 & 38 & 228 & 2 & 2 \\
5.0 to 5.11 & 203 & 31 & 154 & 0 & 12 \\
6.0 to 6.11 & 217 & 37 & 138 & 0 & 8 \\
7.0 to 7.11 & 232 & 41 & 105 & 0 & 22 \\
\hline
\end{tabular}

As indicated in Table III, there was variability between age level, percentile ranking on the NSST, and Intelligence Quotients (I.Q.). When considering the subject population as a whole, over $50 \%$ placed below the 10 th percentile on the NSSP. To determine the correlation between the children's I.Q. and the scores obtained by them on the NSST, Spearman's correlation test was used. The results indicated 
that I.Q. did not correlate with the children's NSST scores. The range for I.Q. was 85 to 115 and in each age group the scores were evenly distributed in this 30 point range.

\section{TABIE III}

PERCENTAGE OF CHILDREN WHO FELL BELOW THE 10th PERCENTILE MEAN I.Q. FOR EACH AGE GROUP

\begin{tabular}{lcccc}
\hline \multicolumn{1}{c}{ Age } & \% below 10th & Mean I.Q. & $\begin{array}{c}\text { Lee Mean } \\
\text { Score }\end{array}$ & Correlation \\
\hline 3.0 to 3.5 & $20 \%$ & 87.8 & 4.3 & -0.12 \\
3.6 to 3.11 & $90 \%$ & 88.6 & 7.2 & .08 \\
4.0 to 4.5 & $90 \%$ & 90.6 & 12.20 & .48 \\
4.6 to 4.11 & $40 \%$ & 93.0 & 13.20 & .38 \\
5.0 to 5.11 & $70 \%$ & 99.5 & 20.30 & .49 \\
6.0 to 6.11 & $80 \%$ & 101.9 & 21.70 & .67 \\
7.0 to 7.11 & $100 \%$ & 91.6 & 23.20 & .15 \\
\hline
\end{tabular}

Mean scores and standard deviations (S.D.) were derived for each of the three predominant categories Lee, Wolfram, and Idiosyncratic. In the lee category the means ranged from 4.3 for the youngest group tested to 23.20 for the oldest group tested. The S.D. ranged from 2.45 for the youngest to 8.80 for the oldest group tested. In the Wolfram category the means ranged from 7.8 for the youngest group to 4.10 for the oldest group. The S.D. ranged from 4.21 for the youngest group to 4.04 for the oldest group. In the Idiosyncratic category the means ranged from 27.40 for the 
youngest to 10.50 for the oldest group tested. The S.D. ranged from 5.72 to 4.91 for the youngest to the oldest respectively.

\section{TABIE IV}

MEAN SCORES AND STANDARD DEVIATIONS FOR IEE, WOLFRAM AND IDIOSYNCRATIC RESPONSES

ON FIRST SCORING

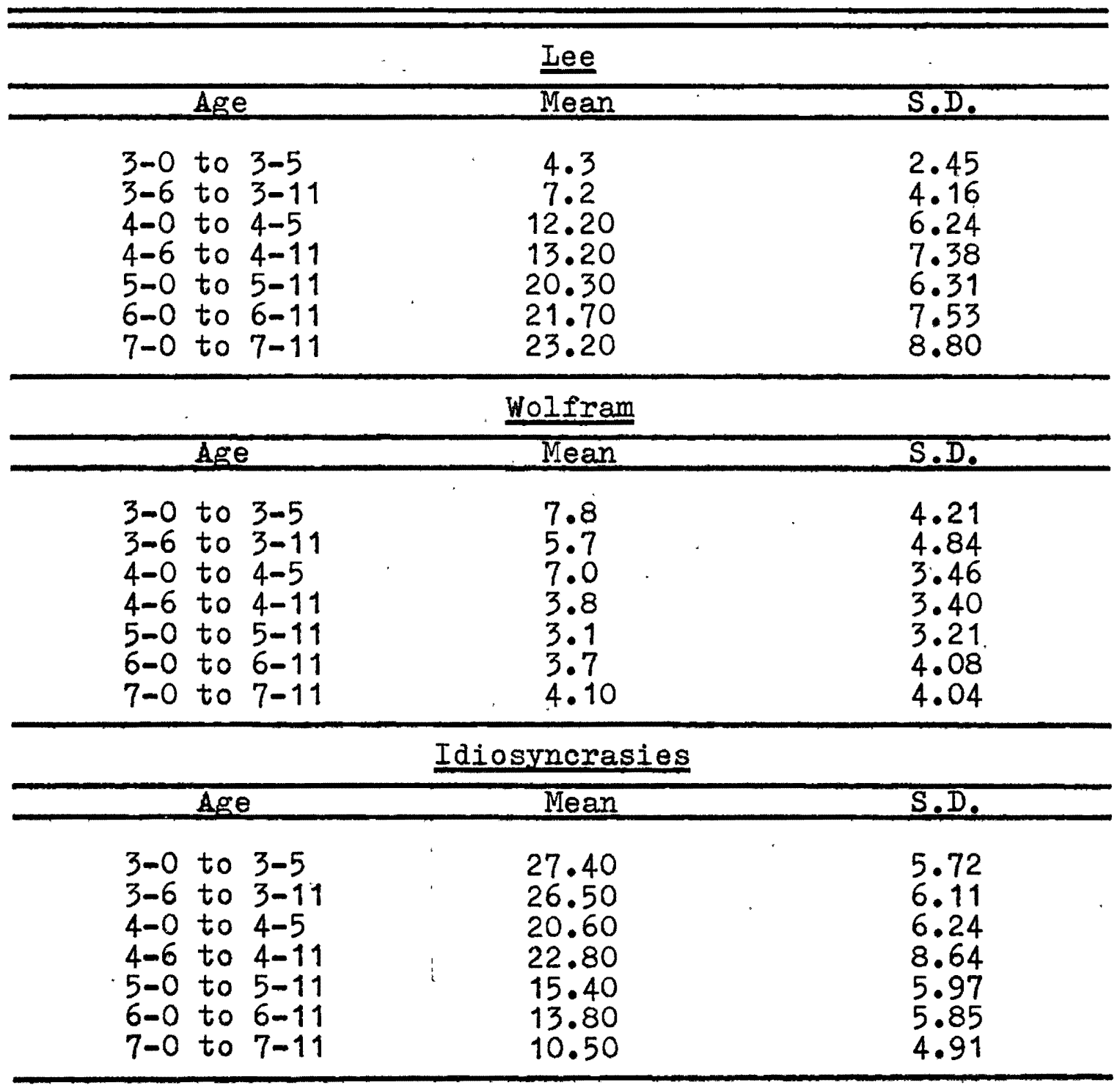


An item analysis for each of the age groups in the five categories was conducted for the results of the second scoring. The responses ranged from 51 Lee, 108 Wolfram, 236 Idiosyncratic, 3 No response, and 2 Reversals for the youngest group tested to 237 Iee, 55 Wolfram, 86 Idiosyncratic, $O$ No response, and 22 Reversals for the oldest group.

\section{TABIE V}

NUMBER OF RESPONSES IN EACH OF FIVE CATEGORIES BY AGE GROUPS ACCORDING TO SECOND SCORING

\begin{tabular}{lccccc}
\hline Age & Iee & Wolfram & Idio. & N.R. & R. \\
\hline 3.0 to 3.6 & 51 & 108 & 236 & 3 & 2 \\
3.6 to 3.11 & 83 & 63 & 247 & 1 & 6 \\
4.0 to 4.5 & 127 & 80 & 189 & 0 & 4 \\
4.6 to 4.11 & 157 & 55 & 184 & 2 & 2 \\
5.0 to 5.11 & 214 & 30 & 135 & 0 & 12 \\
6.0 to 6.11 & 225 & 46 & 121 & 0 & 8 \\
7.0 to 7.11 & 237 & 55 & 86 & 0 & 22 \\
\hline
\end{tabular}

On the second scoring fewer percent fell below the 10 th percentile established by lee for the NSST. These percentiles ranged from $0 \%$ for the youngest group tested to $80 \%$ for the oldest group tested. 
TABLE VI

NUMBER OF CHIIDREN WHO FELI BEIOW THE 10th PERCENTIIE ACCORDING TO THE SECOND SCORING

\begin{tabular}{cc}
\hline \multicolumn{1}{c}{ Age } & $\%$ below 10th \\
\hline 3.0 to 3.5 & $0 \%$ \\
3.6 to 3.11 & $90 \%$ \\
4.0 to 4.5 & $80 \%$ \\
4.6 to 4.11 & $30 \%$ \\
5.0 to 5.11 & $60 \%$ \\
6.0 to 6.11 & $60 \%$ \\
7.0 to 7.11 & $80 \%$ \\
\hline
\end{tabular}

Mean scores and standard deviations (S.D.) were derived for each of the three categories Lee, Wolfram, and Idiosyncratic from the results of the second scoring. In the lee category the means ranged from 5.1 to 23.7 for the youngest group tested to the oldest group. The S.D. ranged from 1.91 to 9.12 from the youngest to the oldest group tested. In the Wolfram category the means ranged from 10.8 for the youngest group to 5.5 for the oldest, and the S.D. ranged from 4.61 for the youngest group to 5.5 for the oldest. In the Idiosyncratic the means ranged from 23.6 to 8.6 in the youngest, and the S.D. ranged from 5.32 in the youngest to 4.5 in the oldest group tested. 
TABIE VII

MEAN SCORES OBTAINED FOR IEEE, WOIFRAM, AND IDIOSYNCRATIC RESPONSES ON SECOND SCORING

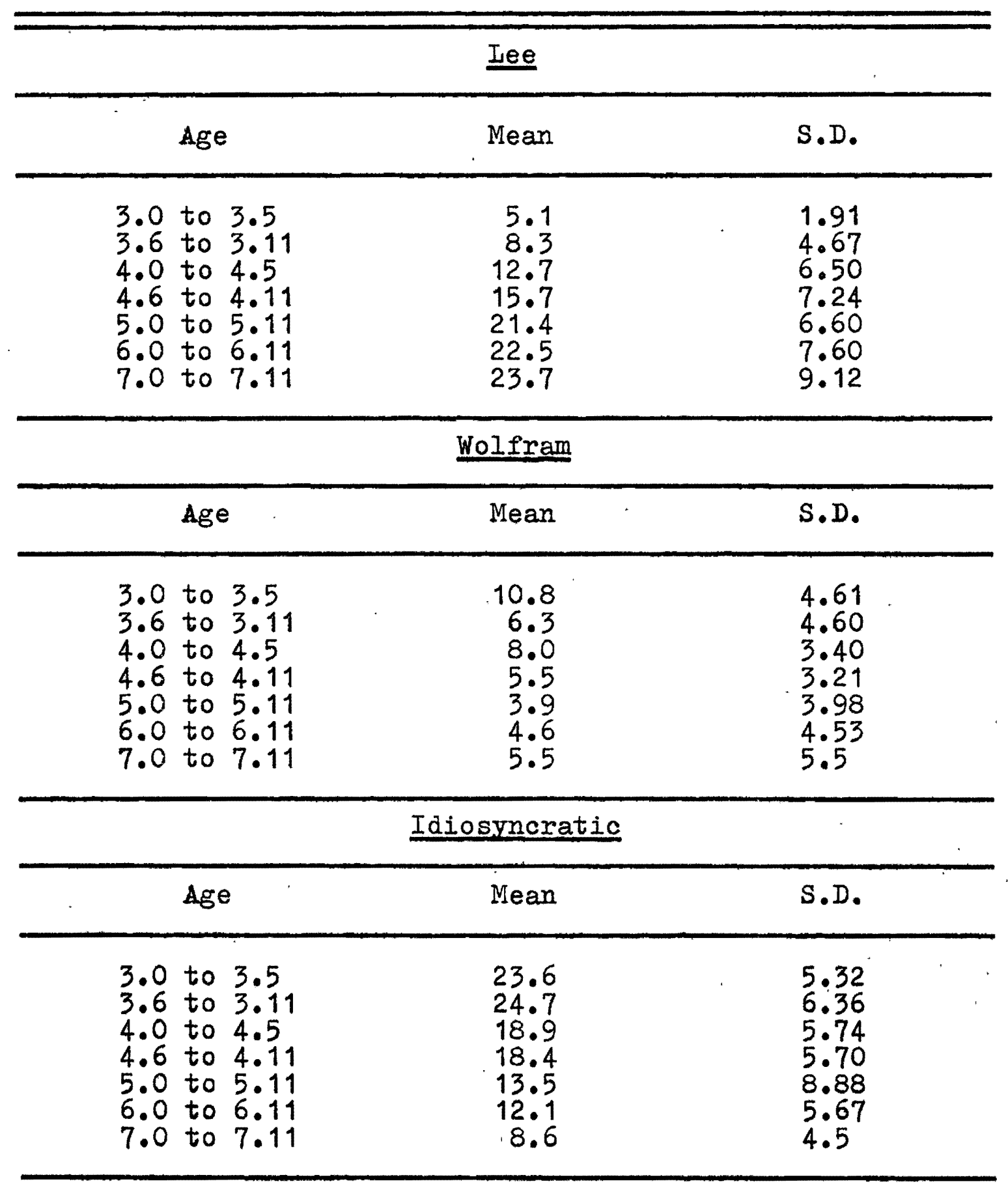


The means were plotted for the Portland black children's first and second scoring and for the population used by Lee to establish norms for this test (Figure 1). The following legend was used: $\Delta=$ Lee's population; $0=$ Portland black children's first scoring; and $D=$ Portland black children's second scoring.

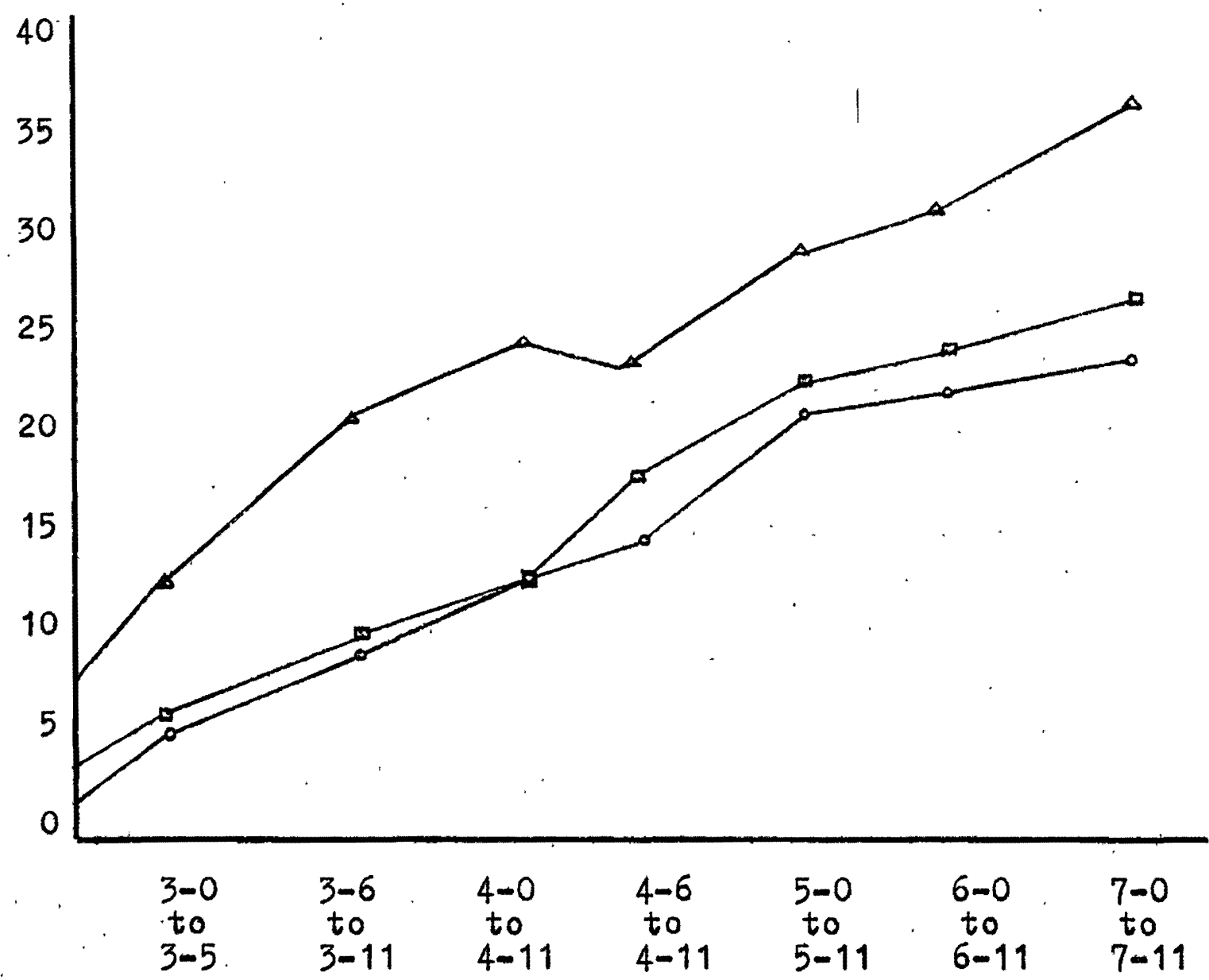

Figure 1. Mean scores for the Portland black children on first and second scorings and for the population used by fiee to establish norms on the NSST.

\section{Discussion}

The primary purpose of this study was to determine if 
Portland black children exhibited dialectal interferences on the NSST. The secondary purpose of this study was to provide suggested norms for differentiating children with language differences from children with language deficits. This researcher predicted that Portland black children would exhibit dialectal interference as described by Walter Wolfram (Appendix B) on the NSST. However the results of this study did not conclusively support this prediction. Due to this finding it was not possible to establish suggested norms. It is felt that such information would be of clinical value to the speech pathologist because it is her job to determine whether a child has a language difference or a language deficit. The literature concerning the language of low income black children suggests two theories appropriately called the deficit and the difference theory. Those who support the deficit view feel that economically disadvantaged black children have a systematic but underdeveloped language which is an approximation of standard English (Bernstein, 1970; Bereiter, 1967; Hess, Shipman and Jackson, 1965). They feel that the black child's speech is characterized by a limited vocabulary and a restricted sentence structure, with only a few constructions which could be matched with standard English. According to these theorists the rest of the child's repertoire consists of unstmactured errors in language behavior. The difference theory states that black children do have a consistent and 
logical language system with its own pronunciation and grammatical patterns.

The findings of this study indicated that Portland black children displayed a mixture of five types of responses. When considering the total population the largest number of responses given were Idiosyncratic, the second largest number of responses were Iee and the third largest number of responses were Wolfram. A small number of responses were Reversals and the least number of responses were in the No response category.

The children in this study increased in linear fashion in correct lee responses over time and Idiosyncratic responses became less and less a part of their verbal repertoire.

In the pre-academic children black language as described by Wolfram accounted for a greater portion of responses than did Lee responses. By academic age there was a small percentage of children studied in which black language tended to stabilize, and remain a significant part of their verbal repertoire (Figure 2). The results of this study, indicate the single best prediction of the pre-academic child's response is that it will be Idiosyncratic. The single best prediction of the academic child's response is that it will be a Lee response.

Idiosyncratic responses were defined as any response which did not fall into a Lee, Wolfram, No response or 


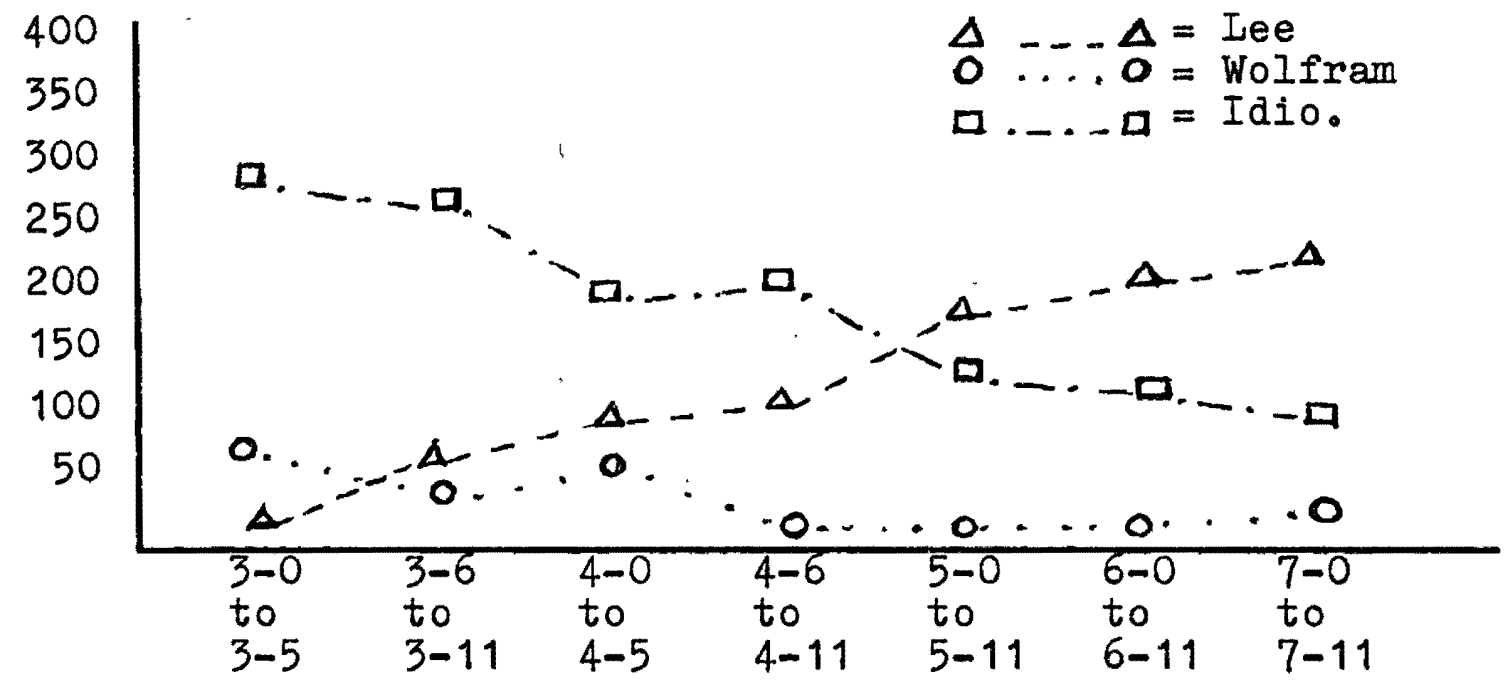

Figure 2. Number of responses in each of five age groups according to the first scoring.

Reversal category and can be further qualified as those responses which were grammatically incorrect and/or generalizations (Appendix C). The Idiosyncratic response then would be indicative of the children who have not yet gained full control of their syntactical abilities. Many of the pre-academic children would still be developing and acquiring syntactical rules. In addition the amount of exposure to formal schooling where "correct syntax" is used would be very limited for these children. Therefore, the high number of idiosyncrasies in language usage in the pre-academic years would be a logical and normal finding.

Lee responses were defined as echoic, verbatim responses or ones which followed the guidelines for insignificant alterations as described in the Rules for Scoring (Appendix C) and can further be qualified as responses typical of white English. The Iee response would be 
indicative of the child who has learned the rules of white middle class syntax. Since most children have acquired the rules of syntax by age of four, the academic aged children should have acquired some or all of the rules governing syntax. These children also have had the most exposure to "correct syntax" through formal schooling. It would appear to be a logical and normal finding then that the academic children exhibit the most Lee responses. Even though the findings indicate that the single best prediction of the academic black child is a Lee response a largex percentage of the academic children scored below the 10th percentile on the NSST than did the pre-academic children. In the pre-academic groups the percentage scoring below increases significantly between the 3-0 to $3-5$ and $3-6$ to $3-11$ groups and decreases significantly between the 4-0 to $4-5$ and $4-6$ to $4-11$ groups. In the academic groups the percentage of children scoring below the 10th percentile increases gradually. The mean scores of the Portland black children were compared with the mean scores of the population used to establish norms on the NSST. Of particular interest is the fact that well over half of the total population of this study scored below the 10th percentile on the NSST. The significance of this according to the NSST is that these children should be evaluated further in terms of syntactical delay. In order to determine whether or not the children's 
I.Q. influenced the scores obtained by them the Spearman's correlation test was used. The results indicated that I.Q. did not correlate with the children's NSST scores and it can be concluded that I.Q. did not influence the results obtained.

If word order and morphological endings remained the same the sentence was scored correctly. In class word substitutions were also scored correctly as were insertions which did not change the meaning of the part. In all groups the number of Tee and Wolfram scores inereased and Idiosyncrasies decreased (Figure 3 ).

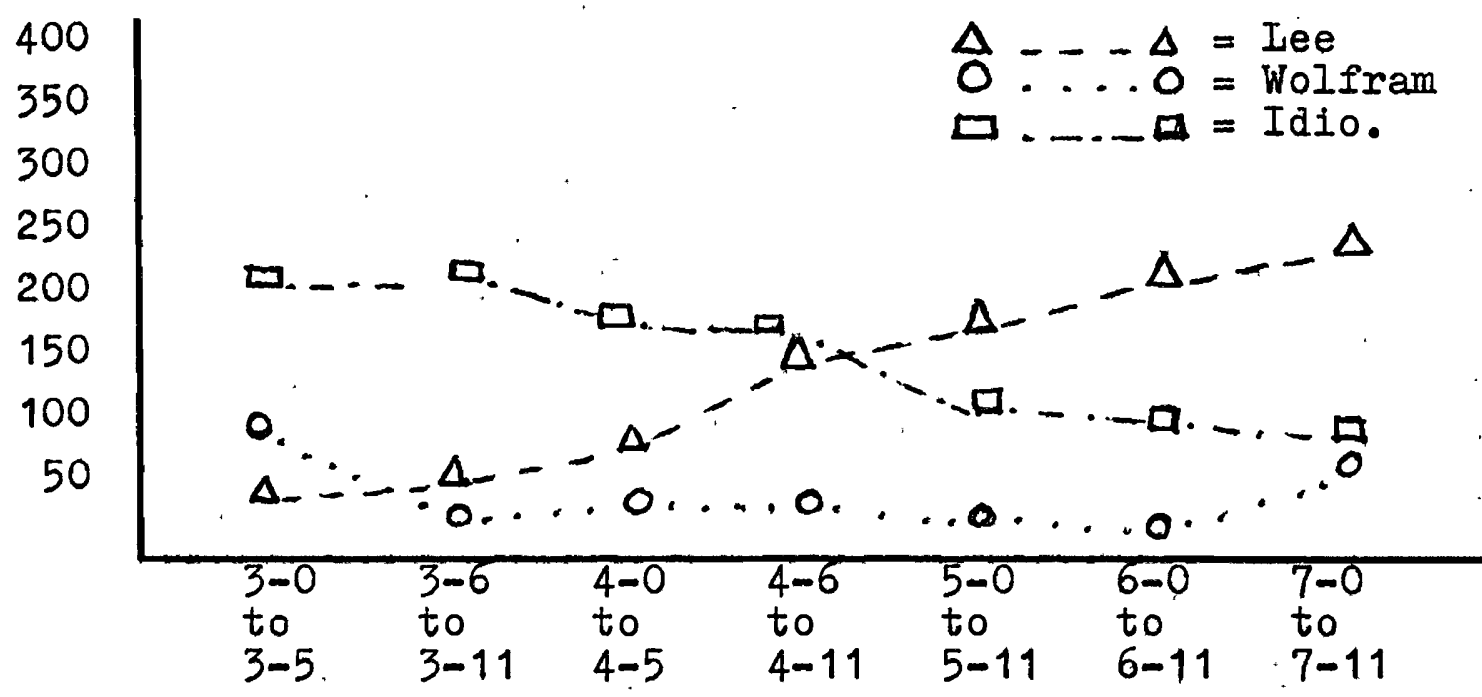

Figure 3. Number of responses in each of five age groups according to the second scoring.

The scores obtained on the second scoring did not significantly alter the results of the first scoring. The second scoring did alter slightly the percentage in each age group who fell below the 10th percentile except for the 3-6 to 
3-11 children but did not indicate that the scoring procedure significantly influenced the number of responses which fell into each category.

The small number of Wolfram responses obtained accounted for less than one-fourth of the total responses and less than one-fourth of the number of responses in each age group, therefore it could possibly be stated that dialectal interference was not a significant influencing factor in the low scores obtained.

Since the factors for which controls were established in this study did not significantly influence the results found, it would appear that the low scores obtained for both Lee and Wolfram indicate these children need further evaluation in terms of syntactic delay. Before such a conclusion is reached several factors for which controls were not established must be considered.

The first would be the possible influence a white tester would have in the type of responses she would illicit from a black child. Studies show the level of anxiety in black subjects with a white tester is high (Baratz, 1967) and the performance of the black subject is likely to be less typical with a white tester than with a black tester (Katz and Greenbaum, 1963). During the course of this study this researcher engaged in a telephone conversation with Laura Lee in which she stated the very nature of a testing situation as well as a white tester 
would prompt the child to attempt a white response. This suggests in such a situation the black child would be aware that black English would not be the acceptable mode of response and this would lead to trial and error behavior which might result in a higher proportion of Idiosyncratic responses.

A second factor to consider is that the NSST was given in white English. This could also establish a situation which prompts the child not to use his own dialect which could also lead to trial and error behavior, resulting in a higher number of idiosyncrasies.

In view of the possible influence of these two factors it is possible that the low scores obtained by the children could be attributed to dialectal interference.

To determine whether the low Lee and Wolfram and high Idiosyncratic scores are indicative of language deficit or language difference a control group should be established. This would consist of a black tester, black children, the NSST given in black English and the same procedures as followed in this study. The results in comparison to this study should indicate whether there is a deficit or difference. If the black control group scored above the 10th percentile or better on the black NSST this would indicate that the children in this study were exhibiting dialectal interference. If the scores obtained by the control group were similar to the scores obtained by the children in 
this study this would indicate that both groups exhibited syntactical deficiency. 


\section{CHAPTER V}

\section{SUMMARY AND IMPIICATIONS}

\section{SUMMARY}

The primary purpose of this study was to determine If dialectal interference as described by Walter Wolfram (Appendix B) was exhibited by black children in Portland, Oregon when given the NSST by Laura Lee. This author was concerned with syntactical interferences on the expressive portion of this test.

A secondary purpose of this investigation was to provide suggested norms for differentiating children with language deficits from children with language differences.

Serenty black children with normal speech and language were selected from two public schools, a Head start Center and a day care center. These children were between the ages of 3-0 to 7-11 and had been screened to determine their race, age, socioeconomic status, and emotional stability. Screening for intelligence was performed at the beginning of the testing situation, before the expressive portion of the NSST was administered. The NSST consists of sentence repetition in response to pictures. The sentences involve grammatical contrasts of increasing difficulty, and can be administered in five to ten minutes. 
The results of this study did not support the prediction made by this researcher. Black dialect was found to account for less than one-fourth of the total number of responses given. Lee responses were low in the pre-academic group but accounted for more than one-half the total number of responses for each age level in the academic group. The Idiosyncratic responses were high in the pre-academic group and accounted for over one-half of the total number of responses within each age group but this type of response markedly decreased in the academic child. In viewing the population as a whole over $50 \%$ of the children placed below the 10th percentile established on the NSST. Results of the Spearman's test of correlation indicated that there was no correlation between the children's I.Q. and score obtained on the NSST. A second scoring administered to the tests using less strict criteria found that the initial scoring miles used had not affected the results of this study.

In considering the total number of responses in each category the Lee and Wolfram responses are low. This can be indicative of either of two theories found in the literature. The difference theorists propose that black children experience academic difficulty in school due to dialectal interference while the deficit theorists feel that the lack of success experienced in school by black children is due to language delay. The results of this study would appear 
to approach the latter view although when considering other variables for which controls were not established such as race of the tester and the dialect of the test given, it appears that it is not possible to draw the conclusion that the results of this study indicate either a language deficit or a language difference.

\section{II.: IMPIICATIONS}

\section{Clinic}

Although the results of this study do not conclusively indicate a. language deficit or difference, this study does evidence some information about Portland black children which could be of value to the speech clinician when dealing with a child in an evaluative setting.

There is black English in Portland but since there are no norms for black English for this area the degree to which these children speak black English is not evident. Also it is apparent from these results that these children are bi-dialectal, and that this ability increases with age, probably due to syntactical development and exposure to white syntax through formal schooling.

Even without existing norms one can still evaluate $a$ black child adequately if remaining aware of the features of black English, of the dialect as it is spoken in the child's home and community, and that younger children will have less bi-dialectal ability. 


\section{Research}

If future research is to be done this author suggests that a control group be established consisting of a black tester, black population, and the NSST in black English. The population and procedures should closely parallel those of this study and comparisons can then be made to determine if Portland black children exhibit a language deficit or a language difference on the NSST. 
Adler, S., Pluralism, relevance, and language, intervention for culturally different children. ASHA, 13 (1971).

Adler, S., Social class bases of language: a reexamination of socioeconomic, sociophysical, and sociolinguistic factors. ASHA, 15 (1973).

Baratz, J., Should Black Children Learn White Dialect? In A. Smith (Ed.), Language Communication and Rhetoric in Black America. New York: Harper and Row (1972).

Baratz, J., Teaching Reading in an Urban Negro School System. In F. Williams, Ianguage and Poverty. Chicago: Markham Publishing company (1970a).

Baratz, J., Quote from W. Wolfram's article, Sociolinguistic premises and the nature of nonstandard dialects. The Speech Teacher, 19 (1970b).

Baratz, J., Who should do what to whom . $:$ and why? Florida Foreign Ianguage Reporter, 7 (1969a).

Baratz, J., Iinguistic and cultural factors in teaching reading to ghetto children. Elementary English, 46 $(1969 b)$.

Baratz, J., A bi-dialectal task for determining language proficiency in economically disadvantaged Negro children. Child Development, 13-14 (1969c).

Baratz, S., The effect of race of the experimenter, instructor and comparison populations upon the level of anxiety in Negro subjects. Journal of Personality and Social Psychology, 7 (1967).

Berieter and Engelmann, Teaching Disadvantaged Children in the Preschool. Engelwood CIiffs, N.J.: Prentice-Hall $(1966)$.

Bernstein, B., A Sociolinguistic Approach to Sociolization with Some Reference to Educatability. In F. Williams (Ed.), Ianguage and Poverty. Chicago: Markham Pubijshing Company (1970). 
Berko, J., The child's learning of English morphology. Word, 13-14 (1958).

Blank, Marion, Language and Poverty. Chicago: Markham Pub. Co. $(1970)$.

Brazziel, W. R., and Terrell, M., An experiment in the development of readiness in culturally disadvantaged group of first-grade children. J. of Negro Education, 31 (1962).

Brittain, C. V., Preschool programs for culturally deprived children. Children, 13-14 (1966).

Bromwich, R., Developing the language of young disadvantaged children. The Education Digest, 33 (1968).

Burks, A., and Guilford, Polly, Wakulla County oral language project. Elementaxy English, 46 (1969).

Caldwell, B., and Richmond, J., Programmed day care for the very young child - a preliminary report. J. of Marriage and the Family, 26 (1964).

Carrow, Sr. M. A., The development of auditory comprehension of language structure in children. J. Speech Hearing Dis., 33 (1968).

Cazden, C., Subcultural differences in child language: an interdisciplinary review. Merrill-Palmer Quarterly, 11-12 (1966).

Clasen, E. E., A comparison of the relative effectiveness of two types of preschool compensatory programming. J. of Educational Research, 59 (1969).

Dilliard, J. I., Black English. New York: Random House (1972).

Dunn, I. M., PPVT. Minneapolis, Minn.: American Guidance Service Inc. (1959).

Erickson, F., 'F' get you honky!': a new look at black dialect and the school. Elementary English (1969).

Fine, Margaret A., Language acquisition and the culturally deprived, an unpublished paper (1972).

Hess, R., Shipman, V., and Jackson, D., Some new dimensions in providing equal educational opportunity. J. of Negro Education, 34 (1965). 
Johnson, K., Should black children learn standard English? In M. Imhoof (Ed.), Viewpoints, 48 (1971).

Johnson, H., Teacher attitude and ghetto language. In M. Imhoof (Ed.), Viewpoints, 48 (1971).

Katz, I., and Greenbaum, C., Effects of anxiety, threat and racial environment on task performance of Negro college students. J. of Abnormal and Social Psyehology, 66 (1963).

Kochman, T., Black Speech Events and a Language Program for the Classroom. In C. Cazden (Ed.), Functions of Language in the Classroom. New York: Teachers College Press (1972).

Kirk, S., McCarthy, J., and Kirk, W., The Illinois Test of Psycholinguistic Abilities (rev. ed.). Urbana: University of Illinois Press (1968).

Lee, I., Developmental sentence types: a method for comparing normal and deviant syntactic development. J. Speech Hearing Dis., 31 (1966).

Lee, I., A screening test for syntax development. I. Speech Hearing Dis., 34-35 (1970).

Lee, I., and Cantor, Susan M., Developmental sentence scoring: a clinical procedure for estimating syntactic development in children's spontaneous speech. J. Speech Hearing Dis., 36 (1971).

Ierea, I., The Michigan Picture Ianguage Inventory. Ann Arbor: University of Michigan (1958).

Lobov, W., Stages in the Acquisition of Standard English. In R. Shuy (Ed.), Social Dialects and Language Learning. Champaign, III.: National Council of Teachers of English (1965).

Lobov, W., The Logic of Nonstandard English. In F. Williams (Ed.), Ianguage and Poverty. Chicago: Markham Pub. Co. $(1970)$.

Menyuk, P., Ianguage Theories and Educational Practices. In F. Williams (Ed.), Ianguage and Poverty. Chicago: Markham Pub. Co. (1970).

Menyuk, P., The Acquisition and Development of Ianguage. Engelwood Cliffs, N.J.: Prentice-Hall, Inc. (1972). 
Menyuk, P., Sentences Children Use. Cambridge, Mass.: M.I.T. Press (1969).

Mitchell-Kernan, C., On the Status of Black English for Native Speakers: An Assessment of Attitudes and Values. In C. Cazdens (Ed.), Functions of Language in the Classroom. New York: Teachers College Press (1972).

Pierce, Joe E., Quote from classnotes, unpublished (1972).

Povich, E. and Boratz, J., An Investigation of Syntax Development of Head Start Children: A Development Sentence Types Analysis, Presented to ASHA, Chicago (1967).

Seymour, Dorothy, Black children, black speech. Commonweal, $6(1971)$.

Shuy, R. W., Sociolinguistic strategies for studying urban speech. In M. Imhoof (Ed.), Viewpoints, 48 (1971).

Shuy, R. W., The Sociolinguistics and Urban Language Problem. In F. Williams (Ed.), Language and Poverty. Chicago: Markham Pub. Co. (1970).

Stewart, W. A., Toward A History of American Negro Dialect. In F. Williams (Ed.), Language and Poverty. Chicago: Markham Pub. Co. (1970).

Swenson, R., and Kristin, G., Toward the Standardized Assessment of the Language of Disadvantaged Children. In F. Williams (Ed.), Ianguage and Poverty. Chicago: Markham Pub. Co. (1970).

U.S. Bureau of the Census, Working Paper Number 15, Mythology and Scoring of Socioeconomic Status, Washington, D.C. $(1963)$.

Williams, F., Ianguage, Attitude and Social Change. In F. Williams (Ed.), Language and Poverty. Chicago: Markham Pub. Co. (1970).

Williams, F., Ianguage, Attitude and Social Change. In Troike and Abrahams (Ed.), Language and Cultural Diversity in America. Chicago (1972).

Wolfram, W., Sociolinguistic premises and the nature of nonstandard dialects. The Speech Teacher, 19 (1970).

Wolfram, W., Black-white speech differences revisited. In M. Imhoof (Ed.), Viewpoints, 48 (1971). 
Wolfram, Handout ASHA Convention (1972).

Yoder, David E., Some Viewpoints of the Speech, Hearing, and Language Clinician. In F. Williams (Ed.), Language and Poverty. Chicago: Markham Pub. Co. $(1970)$. 


\section{APPENDIX A \\ NORTHWESTERN SYNTAX SCREENING TEST \\ RECORD FORM}

Name

Sex

Date

B.D. C.A.

Receptive score Per. Expressive score Per.

Father's occupation Mother's occupation

Examiner Testing location

\section{EXPRESSIVE}

1. The baby is sleeping.

The baby is not sleeping.

2. The $\operatorname{dog}$ is on the box.

The dog is in the box.

3. She sees the car.

He sees the car.

4. The cat is behind the desk.

The cat is under the desk.

5. The boy pulls the girl.

The girl pulls the boy.

6. The fish is swimming.

The fish are swimming. 
7. The girl sees the dog. The girl sees the dogs.

8. This is their wagon.

This is his wagon.

9. The cats play.

The cat plays.

10. Mother says, "Where is that boy?"

Mother says, "Who is that boy?"

11. The boy washes himself.

The boy washes the shelf.

12. This is my dog.

That is my dog.

13. The car is in the garage.

Is the car in the garage?

14. The boy will throw.

The boy is throwing.

15. The boy jumped.

The boy jumps.

16. Mother says, "Look who I found."

Mother says, "Iook what I found." 
17. Has the boy found his ball?

The boy has found his ball.

18. This is a baby doll.

This is baby's doll.

19. The boy is pulled by the girl. The girl is pulled by the boy.

20. The man brings the girl the boy.

The man brings the boy the girl. 


\section{APPENDIX B \\ PREDICTED DIAIECT INTERFERENCE AS DESCRIBED BY WAITER WOIFRAM ON NSST}

1. a The baby is sleeping.

D.V. a The baby sleeping.

b The baby, he sleeping.

b The baby is not sleeping.

D.V. a The baby not sleeping.

$b$ The baby ain't sleeping.

c The baby, he not/ain't sleeping.

2. a The dog is on the box.

D.V. a The dog on the box.

$b$ The dog, he on the box.

b The dog is in the box.

D.V. a The dog in the box.

$b$ The dog, he in the box.

3. a She sees the car.

D.V. a She see the car.

$b$ Her see the car.

b He sees the car.

D.V. a He see the car.

b Him see the car.

4. a The cat is behind the desk.

D.V. a The cat behind the desk.

$b$. The cat, he (be)hind the desk. 
4. Cont.

b The cat is under the desk.

D.V. a The cat under the desk.

$b$ The cat, he/it under the desk.

5. a The boy pulls the girl.

D.V. a The boy pull the girl.

b The boy, he pull the girl.

b The girl pulls the boy.

D.V. a The girl pull the boy.

b The girl, she pull the boy.

6. a The fish is swimming.

D.V. a The fish swimming.

b The fish are swimming.

D.V. a The fish swimming.

$b$ The fishes swimming.

c The fish/es is swimming.

7. a The girl sees the dog.

D.V. a The girl see the dog.

b The girl, she see the dog.

b The girl sees the dogs.

D.V. a The girl see the dogs.

$b$ The girl see the dog.

c The girl, she see the dog/dogs.

8. a This is their wagon.

D.V. a This their wagon.

b This they wagon.

c Here go the wagon.

b This is his wagon.

D.V. a This his wagon.

b This he wagon.

c Here go the wagon. 
9. a The cats play.

D.V. a The cat play.

b The cat plays.

D.V. a The cat play.

10. a Mother says, "Where is that boy?"

D.V. a Mother say, "Where that boy/at?"

b Mother, she say, "Where that boy/at?"

c Mother say, "Where that boy is?"

b Mother says, "Who is that boy?"

D.V. a Mother say, "Who that boy?"

b Mother say, "Who that boy is?"

c Mother, she say, ...

11. a The boy washes himself.

D.V. a The boy wash hisself.

b The boy washing himself/hisself.

c The boy, he washing himself/hisself.

b The boy washes the shelf.

D.V. a The boy wash the shelf.

b The boy, he wash the shelf.

12. a This is my dog.

D.V. a This my dog.

$b$ This here my dog.

c Here go my dog.

b That is my dog.

D.V. a That my dog.

b Tha's my dog.

c Here go my dog.

13. a The car is in the garage.

D.V. a The car in the garage? 
13. Cont.

b Is the car in the garage?

D.V. a The car in the garage?

(With question intonation.)

14. a The boy will throw.

D.V. a The boy gonna throw.

b The boy throw.

b The boy is throwing.

D.V. a The boy throwing.

b The boy, he throwing.

15. a The boy jumped.

D.V. a The boy jump.

b The boy Jumps.

D.V. a The boy jump.

b The boy, he jump.

16. a Mother says, "Look who I found."

D.V. a Mother say, "Iookit who I found."

b Mother, she say, "Iook who I found."

b Mother says, "Iook what I found."

D.V. a Mother say, "Look/it what I found."

b Mother, she say, "Iook/it what I found."

17. a Has the boy found his ball?

D.V. a The boy find/found the/his ball?

$b$ Is the boy find/found the/his ball?

b The boy has found his ball.

D.V. a The boy found the/his ball.

$b$ The boy, he found his/the ball. 
18. a This is a baby doll.

D.V. a This a baby doll.

b This is baby's doll.

D.V. a This baby doll.

19." a The boy is pulled by the girl.

D.V. a The boy pull by the girl.

$b$ The girl is pulled by the boy.

D.V. a The girl pull by the boy.

20. a The man brings the girl the boy.

D.V. a The man bring the girl the boy.

$b$ The man bring the girl to the boy.

c The man, he bring/bringing ...

b The man brings the boy the girl.

D.V. a The man bring the boy the girl.

$b$ The man bring the boy to the girl. 


\section{APPENDIX C}

RULES FOR SCORING THE NSST

1. If a child restructures and/or semantically changes the first pair of sentences on the NSST after correctly replying to the sample pictures, then the examiner will repeat the entire first pair.

2. When the child generalizes on a sentence which describes the picture rather than responding with one of the two sentences presented by the examiner, the child will be reinstructed and the entire task will be repeated again.

3. If the child indicates by stopping that he doesn't remember the whole phrase, the examiner will repeat the entire task once again.

4. Reversals are scored incorrect, that is when the child says a grammatically correct sentence to the wrong picture.

5. The carrier phrase in sentences \#10 and \#16 will be scored if the child says them, but if left out the examiner will score only what the child says.

6. Word substitutions are incorrect such as: the article a will not be accepted for the article the.

7. Contractions are scored as correct, example: the baby's sleeping. 
8. When the child inserts a word which is correct but not verbatim of the sentence presented to him, such as, The dog is standing on the box, for the dog is on the box, the examiner will ask the child to say what the examiner says and repeat the entire task again. The sentence with an insertion will be scored incorrect.

9. Articulation errors will be disregarded unless they affect syntax. 
APPENDIX D

SAMPLES OF IEEE, WOLFRAM, AND

IDIOSYNCRATIC RESPONSES

1. A. (a) The baby is sleeping.

(b) The baby sleeping.

(c) Baby sleep.

B. $\left\{\begin{array}{l}\text { a) The baby is not sleeping. } \\ \text { b) The baby not sleeping. } \\ \text { c }\end{array}\right.$

2. A. (a) The dog is on the box.

(b) The dog on the box.

(c) The dog behind the box.

B. (a) The dog is in the box.

(b) The dog in the box.

3. A. (a) She sees the car.

(b) She see the car.

(c) The girl seeing the car.

B. (a) He sees the car.

4. A. (a) The cat is behind the desk.

(b) The cat behind the desk.

(c) The cat is by desk.

B. (a) The cat is under the desk.

(b) The cat under the desk.

5. A. (a) The boy pulls the girl.

(b) The boy pull the girl.

(c) The boy pullin the girl. 
5. Cont.

B. $\left\{\begin{array}{l}\text { a) The girl pulls the boy. } \\ \text { b) The girl pull the boy. } \\ \text { c The girl pullin the boy. }\end{array}\right.$

6. A. $\left\{\begin{array}{l}\text { a) The fish is swimming. } \\ \text { b } \\ \text { che fish swimming. }\end{array}\right.$

B. (a) The fish are swimming.

(b) The fishes swimming.

(c) Two fishes swimming.

7. A. (a) The girl sees the dog.

(b) The girl see the dog.

B. (a) The girl sees the dogs.

(b) The girl see the dog.

(c) The dog is seein the girl.

8. A. (a) This is their wagon.

(b) This they wagon.

B. $\left\{\begin{array}{l}\text { a) This is his wagon. } \\ \text { b } \\ \text { chis his wagon. }\end{array}\right.$

9. A. (a) The cats play.

(b) The cat play.

(c) The cat playses.

B. $\left\{\begin{array}{l}\text { a) The cat plays. } \\ \text { b) The cat play. } \\ \text { c The cats plays. }\end{array}\right.$

10. A. (a) Mother says, "Where is that boy?"

(b) Mother say, "Where that boy?"

(c) Mother said, "Where's that boy?"

B. (a) Mother says, "Who is that boy?"

(b) Mother say, "Who that boy?"

(c) Mother said, "Where the boy?" 
11. A. $\left\{\begin{array}{l}\text { a) The boy washes himself. } \\ \text { b) The boy wash hisself. } \\ \text { c The boy washes. }\end{array}\right.$

B. $\left\{\begin{array}{l}\text { a) The boy washes the shelf. } \\ \text { b) The boy wash the shelf. } \\ \text { c The boy washes the sheifs. }\end{array}\right.$

12. A. (a) This is my dog.

(b) This my dog.

(c) That is her dog.

B. $\left\{\begin{array}{l}\text { a) That is my dog. } \\ \text { b) That my dog. } \\ \text { c) That's his dog. }\end{array}\right.$

13. A. (a) The car is in the garage.

(b) The car in the garage?

(c) The car's not in the garage.

B. (a) Is the car in the garage?

(b) The car in the garage?

(c) The car is in the garage.

14. A. (a) The boy will throw.

(b) The boy gonna throw.

(c) The boy throwing.

B. (a) The boy is throwing.

(b) The boy throwing.

(c) A boy is not throwing.

15. A. (a) The boy jumped.

(b) The boy jump.

B. $\left\{\begin{array}{l}\text { a) The boy jumps. } \\ \text { b) The boy jump. } \\ \text { c) The boy mun. }\end{array}\right.$

16. A. (a) Mother says, "Look who I found."

(b) Mother say, "Lookit who I found."

B. (a) Mother says, "Iook what I found."

(b) Mother say, "Look what I found."

(c) Mother said, "Look what I found." 
17. A. (a) Has the boy found his ball?

(b) The boy find his ball?

(c) The boy have found his ball?

B. (a) The boy has found his ball.

(b) The boy found his ball.

(c) The boy find his ball.

18. A. (a) This is a baby doll.

(b) This a baby doll.

(c) This is baby's doll.

B. (a) This is baby's doll.

(b) This baby doll.

(c) This is doll.

19. A. (a). The boy is pulled by the girl.

(b) The boy pull by the girl.

(c) The boy pulls the girl.

B. (a) The girl is pulled by the boy.

(b) The girl pull by the boy.

(c) The girl is pulling the boy.

20. A. (a) The man brings the girl the boy.

(b) The man bring the girl the boy.

B. (a) The man brings the boy the girl.

(b) The man bring the boy the girl.

(c) The man brings the boy. 